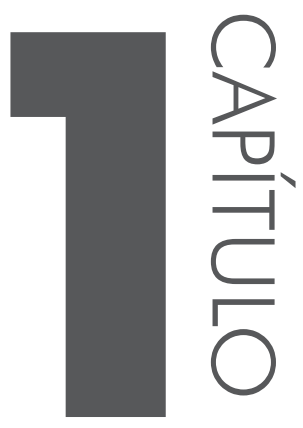

\title{
POLÍTICAS DE SEGURANÇA PÚBLICA E DIREITOS HUMANOS EM SANTA CATARINA
}

\author{
Daiane Oliveira João \\ Giovani Mendonça Lunardi \\ Marta Adriano da Silva Cristiano
}

\section{INTRODUÇÃO}

O debate e as agendas em torno dos temas da Segurança Pública e Direitos Humanos no Brasil estão, hoje, entre as questões mais importantes no que tange a consolidação dos direitos civis e sociais dos cidadãos brasileiros. Neste sentido, o Governo Federal vem ao longo dos últimos anos desenvolvendo várias políticas públicas nacionais de Segurança e Direitos Humanos (BRASIL, 2015).

Destacam-se como ações estratégicas: a consolidação do Sistema Único de Segurança Pública (Susp), os programas da Secretaria Nacional de Segurança Pú- 
blica do Ministério da Justiça (Senasp/MJ), o Programa Nacional de Segurança Pública com Cidadania (Pronasci), a criação da Rede Nacional de Altos Estudos em Segurança Pública (Renaesp) e a Matriz Curricular Nacional para Ações Formativas dos Profissionais da Área da Segurança Pública. Da mesma forma, são relevantes a implementação de critérios qualitativos para a distribuição dos recursos do Fundo Nacional de Segurança Pública. No âmbito das políticas públicas de Direitos Humanos, vale ressaltar a terceira edição do Programa Nacional de Direitos Humanos (PNDH-3), o Plano Nacional de Educação em Direitos Humanos (PNEDH) e as várias ações desenvolvidas pela Secretaria de Direitos Humanos da Presidência da República (SDH/PR).

Por sua vez, a prestação de serviços públicos de segurança inclui o policiamento ostensivo, a apuração de infrações penais e a guarda e recolhimento de presos. O foco das políticas de segurança pública é proteger a cidadania, prevenindo e controlando manifestações da criminalidade e da violência, efetivas ou potenciais, garantindo o exercício pleno da cidadania nos limites da lei (SANTA CATARINA, 2015). Então, como se fala tanto em políticas de segurança pública e, ainda assim, temos uma sensação crescente de aumento da violência urbana?

Devido a este questionamento, o problema da violência tornou-se objeto de interesse e discussão de especialistas e da população em geral. A sociedade brasileira tem acompanhado o aumento da violência e da criminalidade e também observado a falta de respostas por parte das polícias e da Justiça quanto ao enfrentamento do crime e das altas taxas de impunidade.

Trata-se de um problema social que gera ampla mobilização da opinião pública, além de causar impacto sobre o sistema de justiça criminal, que precisa formular e implementar políticas públicas penais, e também no Estado, que precisa adequar suas políticas de segurança pública de modo a diminuir não somente o crime, mas principalmente a insegurança generalizada da sociedade. No Estado de Santa Catarina, a situação não é muito diferente do quadro geral do País: os ataques criminosos vêm aumentando consideravelmente, mesmo com as iniciativas do governo e as novas políticas de segurança pública.

A mídia tem apresentado uma série de atentados criminosos pelo estado, o que faz parecer que a violência se tornou o meio padrão de protesto. Em 2013, ocorreram mais de 82 atentados a ônibus em 26 municípios. Em 2014, os números foram ainda piores: além de ocorrerem em maior número, os atentados também foram mais violentos e duraram mais dias. Pessoas suspeitas de cometerem crimes foram linchadas em diversos municípios de Santa Catarina e os agressores eram familiares e amigos de vítimas, que decidem agir por conta própria.

Florianópolis passou por vários episódios nos quais que toda a população foi afetada não somente pela violência, mas também pela reclusão, por não po- 
der ir e vir livremente, por ter toque de recolher, pelos ônibus que deixaram de circulam entre às 23 horas e às 6 horas. Penalidade para a sociedade e não para os criminosos.

Em vista dos inúmeros projetos de segurança pública que visam inibir a prática criminosa e agilizar o tempo de resposta no atendimento às ocorrências, busca-se com esta pesquisa entender porque os fatos divulgados pela mídia e as incidências de crimes cada vez mais constantes indicam o contrário do que é proposto pelos programas instituídos. Essas políticas de segurança pública estão realmente sendo aplicadas? A partir deste questionamento, neste capítulo serão examinadas as políticas de segurança pública e os direitos humanos implantados no Brasil e no Estado de Santa Catarina a partir dos Planos Nacionais no período de 2005 a 2013.

\section{PLANOS NACIONAIS DE SEGURANÇA PÚBLICA}

A Constituição brasileira de 1988 , em seu artigo $5^{\circ}$, apresenta o direito à segurança como um dos direitos fundamentais, de igual importância ao direito à vida, à liberdade, à igualdade e à propriedade. O legislador constituinte também expressou a prioridade do tema da segurança enquanto preocupação da sociedade em geral.

Entretanto, os governantes, no sentido de responder a esta preocupação relacionada com a segurança enquanto política pública, apresentaram ações de caráter restritivo e aporético aos demais direitos fundamentais, como: sistemas de vigilância, leis penais mais severas, controle de imigração etc. Estas ações polarizam duas reivindicações da sociedade, que são a garantia dos direitos individuais e a emergência do direito à segurança.

De certa forma, colocam-se como opostos aquilo que possuem a mesma essência. De um lado, tem-se a criação de uma série de mecanismos para garantia dos direitos individuais, como a inviolabilidade do domicílio, a proibição de prisões ilegais, o instituto do habeas corpus, a garantia de ampla defesa aos acusados etc. De outro lado, o direito à segurança enquanto política pública teve como principais ações a militarização do policiamento preventivo e ostensivo, transformando "os agentes policiais em uma facção deslocada da sociedade civil, exorbitando em sua prática de vigilância e defesa para a agressão e extermínio" (BRAGA JÚNIOR, 2009, p. 453).

Todas as promessas de repressão à violência endêmica na sociedade brasileira não conseguem ir além do imediatismo eleitoreiro de fácil assimilação. Braga Júnior cita a aplicação de penas mais severas, o aumento do policiamento ostensivo, a elevação dos sistemas de vigilância, entre outros exemplos que remetem a promessas de campanha eleitoral. Ou seja, são ações que vão de encontro aos 
direitos individuais. Assim, a situação social brasileira referente à segurança pública, divide as atividades do Estado em positivas e negativas, restando ao aparato policial somente as de caráter negativo (BRAGA JÚNIOR, 2009, p. 453).

\section{POLÍTICAS DE SEGURANC̣A PÚBLICA: FHC, LULA E DILMA}

Questões de segurança pública passaram a ser consideradas de fundamental importância para a sociedade nos últimos anos e têm recebido atenção especial do Governo Federal. A visibilidade pública que a segurança ganhou é inédita neste país; até então, não se tinha visto tamanha repercussão nem estado tanto em destaque na mídia e em debates como tem sido atualmente. $\mathrm{O}$ aumento considerável da criminalidade despertou o interesse de muitos estudiosos e colocou a segurança como principal desafio para o Estado. Os problemas a se resolver são muitos, e na tentativa de solucioná-lo, o governo cria planos e estratégias que visam reprimir a criminalidade e manter a segurança pública.

Trata-se, pois, a política pública, de uma estratégia de ação pensada, planejada e avaliada, guiada por uma racionalidade coletiva na qual tanto o Estado como a sociedade desempenham papéis ativos. Eis porque o estudo da política pública é também o estudo do Estado em ação (Meny e Toenig) nas suas permanentes relações de reciprocidade e antagonismo com a sociedade, a qual constitui o espaço privilegiado das classes sociais (Ianni) (PEREIRA, 2009, p. 96).

Outra definição ainda para política pública é a colocada por Souza, em que destaca:

Pode-se, então, resumir política pública como o campo do conhecimento que busca, ao mesmo tempo, "colocar o governo em ação" e/ou analisar essa ação (variável independente) e, quando necessário, propor mudanças no rumo ou curso dessas ações (variável dependente). A formulação de políticas públicas constitui-se no estágio em que os governos democráticos traduzem seus propósitos e plataformas eleitorais em programas e ações que produzirão resultados ou mudanças no mundo real (SOUZA, 2006, p. 26).

Por estas razões, foram criados alguns programas no intuito de diminuir as recorrentes reivindicações da sociedade por segurança, possibilitando a tradução de Políticas Públicas de Segurança em Programas de Trabalho, como são apresentados na sequência.

\subsection{Secretaria Nacional de Segurança Pública}

Em 1995, por meio da Medida Provisória no 813, foi criada pelo Governo Federal a Secretaria de Planejamento de Ações Nacionais de Segurança Pública 
(Seplanseg), no âmbito do Ministério da Justiça. Em decorrência de transformação da Seplanseg, foi criada a Senasp, pelo Decreto $n^{\circ} 2.315$, de 4 de setembro de 1997, tendo como perspectiva atuar de forma articulada com os estados da Federação para a implementação da Política Nacional de Segurança Pública (PNSP). A instituição da Senasp como órgão executivo significou a estruturação de mecanismos de gestão capazes de modificar o arranjo institucional da organização administrativa da segurança pública no âmbito do Governo Federal.

\subsection{Plano Nacional de Segurança Pública}

Em 1996, o governo Fernando Henrique Cardoso criou o Programa Nacional de Direitos Humanos (PNDH), tendo por base os fundamentos da Conferência Mundial de Direitos Humanos, ocorrida em Viena, em 1993. O foco do programa era, principalmente, a preservação das liberdades civis em função das recorrentes reclamações da sociedade frente ao uso de violência por parte de policiais. Este programa foi substituído mais tarde pelo II Programa Nacional de Direitos Humanos, instituído no segundo governo FHC, em 2000. Surgiu então, neste mesmo ano, o PNSP, que tem o objetivo de aperfeiçoar as ações dos órgãos de segurança pública, com propostas que integram políticas de segurança, políticas sociais e ações comunitárias, buscando reprimir e prevenir o crime e reduzir a impunidade, elevando o índice de segurança do cidadão.

Para dar apoio financeiro aos projetos do PNSP e à prevenção à violência, foi instituído no âmbito do Ministério da Justiça, também no ano 2000, o Fundo Nacional de Segurança Pública (FNSP). O FNSP apoia projetos na área de segurança pública destinados ao reequipamento, ao treinamento e à qualificação das polícias civis e militares, corpos de bombeiros militares e guardas municipais; sistemas de informações, de inteligência e de investigação, bem como de estatísticas policiais; estruturação e modernização da polícia técnica e científica; programas de polícia comunitária e programas de prevenção ao delito e à violência, entre outros. Ainda assim, esses avanços na formatação da política de segurança pública não produziram os resultados concretos esperados. De acordo com Fernando Salla:

[...] o Plano Nacional de Segurança Pública [...] compreendia 124 ações distribuídas em 15 compromissos que estavam voltadas para áreas diversas como o combate ao narcotráfico e ao crime organizado; o desarmamento; à capacitação profissional; e ao reaparelhamento das polícias, à atualização da legislação sobre segurança pública, à redução da violência urbana e ao aperfeiçoamento do sistema penitenciário. Uma novidade é que no plano, além dessas iniciativas na área específica de segurança, eram propostas diversas ações na esfera das políticas sociais. O plano, no entanto, não fixava os recursos nem as metas para ações. Ao mesmo tempo, não estavam estabelecidos quais seriam os mecanismos de gestão, acompanhamento e avaliação do plano (SALLA, 2003, p. 430). 
O PNSP do governo Fernando Henrique Cardoso, assim como a política de segurança pública adotada no primeiro governo do presidente Luiz Inácio Lula da Silva, não teve os resultados esperados. Questões relacionadas à segurança pública, diante de sua amplitude e complexidade, não podem ser tratadas como política limitada de governo. Para ter êxito, elas devem ser enfrentadas tanto pelo Estado quanto pela sociedade.

As políticas públicas de segurança, justiça e penitenciárias não têm contido o crescimento dos crimes, das graves violações dos direitos humanos e da violência em geral. A despeito das pressões sociais e das mudanças estimuladas por investimentos promovidos pelos governos estaduais e federal, em recursos materiais e humanos e na renovação das diretrizes institucionais que orientam as agências responsáveis pelo controle da ordem pública, os resultados ainda parecem tímidos e pouco visíveis (ADORNO, 2002, p. 8).

\subsection{Sistema Único de Segurança Pública}

O Sistema Único de Segurança Pública (Susp), lançado em abril de 2003, foi criado com o objetivo de promover a integração e a articulação das ações federais, estaduais e municipais nas áreas de Segurança Pública e da Justiça Criminal. A articulação seria por meio da integração desses órgãos, e não pela unificação; a autonomia federativa, assegurada pela Constituição Federal, é preservada. Estados, Polícia Civil e Polícia Militar permanecem cumprindo suas responsabilidades, de forma autônoma, porém passam a utilizar um sistema único, com intuito de prevenir e planejar ações estratégicas. A participação do Estado no SUSP dá-se por meio da criação de um Comitê de Gestão Integrada, do qual fazem parte o secretário estadual de Segurança Pública, representantes da Polícia Federal, Rodoviária Federal, Civil e guardas municipais. A função desse comitê é definir as ações a serem tomadas para combater o crime, atuando principalmente contra o crime organizado (tráfico de drogas e de armas, contrabando, lavagem de dinheiro, pirataria).

As polícias Civil e Militar passaram a integrar a mesma academia e ter acesso à formação prática e teórica de igual conteúdo. Também foi estimulada pelo governo a criação de unidades policiais integradas, com forças das polícias civil e militar, em um mesmo espaço físico.

De acordo com a Senasp, o Susp está definido sob seis eixos:

- Gestão unificada da informação: todas as demandas na área de segurança pública são recebidas por uma central, que as coleta e registra em um banco de dados único, auxiliando na redução da violência e na prevenção ao crime.

- Gestão do sistema de segurança: institui perícia em delegacias, polícia civil e polícia militar, que deverão ser implantadas para cuidar de determinadas áreas geográficas das cidades. 
- Formação e aperfeiçoamento de policiais: treinamento para policiais civis e militares em academias integradas.

- Valorização das perícias: como fase relevante da investigação dos crimes.

- Ações concretas para a prevenção e redução da violência: nos estados, essas ações serão prioritárias, com papel fundamental da polícia comunitária nesse processo.

- Criação de ouvidorias independentes e corregedorias unificadas: as ouvidorias receberão as reclamações da população e identificar possíveis abusos da ação policial, e as corregedorias dever]ao fiscalizar os atos dos policiais civis e militares.

\subsection{Programa Nacional de Segurança Pública com Cidadania}

A partir de 2007, já no segundo mandato do presidente Lula, foi apresentado um novo programa na área da segurança pública, o Programa Nacional de Segurança Pública com Cidadania (Pronasci), aprovado por unanimidade no Congresso Nacional. O Pronasci foi instituído pela Lei ${ }^{\circ} 11.530$, de 24 de outubro de 2007, e traz a violência como um fenômeno decorrente de diversos fatores, colocando como origens da violência e da criminalidade áreas como a educação, saúde e cultura (BRASIL, 2007).

Art. 1ํ - Fica instituído o Programa Nacional de Segurança Pública com Cidadania - PRONASCI, a ser executado pela União, por meio da articulação dos órgãos federais, em regime de cooperação com Estados, Distrito Federal e Municípios e com a participação das famílias e da comunidade, mediante programas, projetos e ações de assistência técnica e financeira e mobilização social, visando à melhoria da segurança pública.

Art. $2^{\circ}$ - O Pronasci destina-se a articular ações de segurança pública para a prevenção, controle e repressão da criminalidade, estabelecendo políticas sociais e ações de proteção às vítimas.

O Pronasci marca uma iniciativa relevante no enfrentamento ao crime no país. O programa tem a finalidade de articular ações de segurança pública, priorizando a prevenção, o controle e a repressão da criminalidade, e estabelecendo políticas sociais e ações de proteção às vítimas da violência. Busca atingir as causas que levam à violência, na intenção de evitá-la.

Muitos pontos merecem destaque no Pronasci, como a valorização dos profissionais de segurança pública, a reestruturação do sistema penitenciário, o combate à corrupção policial e o envolvimento da comunidade na prevenção da 
violência. O programa é dividido em 94 projetos que, para sua execução, contam com atuação da União, dos estados, dos municípios e da comunidade. A seguir, detalham-se alguns deles:

a) Mulheres da Paz: destina-se à capacitação de mulheres socialmente atuantes nas áreas geográficas atendidas pelo Pronasci.

b) Proteção de Jovens em Território Vulnerável - Protejo: Voltado à formação e inclusão social de jovens e adolescentes expostos à violência doméstica ou urbana nas áreas abrangidas pelo Pronasci.

c) Bolsa-Formação: benefício concedido aos profissionais de segurança pública como incentivo ao estudo e à atuação junto às comunidades. Policiais civis e militares, bombeiros, peritos e agentes penitenciários de baixa renda que participarem e forem aprovados em cursos de capacitação promovidos, credenciados ou reconhecidos pela Senasp, do Ministério da Justiça, terão acesso a uma bolsa de até R \$ 400 .

d) Plano Nacional de Habitação para Profissionais de Segurança Pública: os profissionais na segurança pública também podem contar com o benefício no valor de até $\mathrm{R} \$ 50$ mil, para aqueles que recebam até $\mathrm{R} \$ 4.900,00$, em forma de unidades populares e cartas de crédito para a compra da casa própria.

e) Formação Policial: oferta, por meio da Renaesp, de cursos para a qualificação das polícias, que inclui práticas de segurança cidadã, como a utilização de tecnologias não letais, direitos humanos, entre outros.

f) Sistema Prisional: criação de novas vagas no sistema penitenciário do país destinadas a públicos específicos. O objetivo é separar os detentos por faixa etária e por natureza do delito, para impedir que aqueles que cometeram pequenas infrações fiquem sob a influência dos líderes do crime organizado.

O Estado de Santa Catarina aderiu ao Pronasci em 2011, durante o governo Raimundo Colombo.

\section{SANTA CATARINA: IMPACTOS DOS PLANOS NACIONAIS - 2005 A 2013}

No Estado de Santa Catarina, são inúmeros os projetos em andamento que visam reduzir o número de crimes e a insegurança. O governo estadual tem dado atenção especial à Segurança Pública. Em 2012, por exemplo, foi lançado o Pacto pela Segurança Pública, Justiça e Cidadania, com a proposta de modernizar e ampliar o serviço das polícias civil e militar, corpo de bombeiros e 
do Instituto Geral de Perícias. Entre as medidas do programa, destacam-se os investimentos com vídeomonitoramento por câmeras de segurança na maioria das cidades catarinenses, cujo objetivo é reduzir o índice de criminalidade no Estado.

O Governo do Estado declarou, em 2012, que estava investindo constantemente na ampliação do sistema de vídeomonitoramento por câmeras de segurança. A proposta do Pacto previa a instalação de câmeras principalmente em locais com grande circulação de pessoas, como praças e nas proximidades de agências bancárias e de escolas. A parceria foi feita com os municípios, que firmaram convênio com o governo e escolheram o projeto para a instalação de seis a dez câmeras, com valores que variavam entre $\mathrm{R} \$ 80$ mil a $\mathrm{R} \$ 105$ mil.

Preocupado com o aumento elevado dos índices de criminalidade no Estado, o governo criou uma série de programas que visa à prevenção do crime, e não apenas a atuação imediata e corretiva de crises. Dentre esses programas, que são reflexos da preocupação nacional com a segurança, destacam-se: Programa $\mathrm{Mu}$ nicípio Seguro, Polícia Comunitária, Programa Segurança Mirim, Programa De Olho Na Rua etc.

Por sua vez, os investimentos em Segurança Pública ficaram a cargo do programa Pacto por Santa Catarina, que reúne obras e aquisições para atender às principais demandas da sociedade. É um programa de gestão dos projetos, alguns já implantados ou em vias de implantação, que vem recebendo investimentos consideráveis. O Pacto foi lançado em julho de 2012, no governo Raimundo Colombo, com o intuito de abranger os projetos em andamento em um único programa de gestão.

Seus recursos destinam-se a investimentos em áreas estruturantes da Segurança Pública. A proposta foi de que, nos anos de 2013 e 2014, o governo estadual, por meio da Secretaria de segurança Pública, destinaria R 265 milhões para investimentos essa área. Por ser um programa aberto, o Pacto pode agregar novas iniciativas e recursos, sendo que inicialmente o foco são a mobilidade policial, os equipamentos, a estrutura e o monitoramento urbano. Esses investimentos potencializam os serviços no enfrentamento da violência, em que a comunidade será beneficiada com o aumento da segurança e a diminuição dos índices de criminalidade.

\section{RESULTADOS}

Controlar a ordem pública é cada vez mais difícil e complexo. O aumento das taxas de criminalidade, a sensação de insegurança que de forma generalizada toma conta do país, os inúmeros registros de violência policial e violação de direitos humanos, a superlotação dos presídios, a falta de programas de ressocia- 
lização, as rebeliões, os atos violentos cometidos por populares, a degradação do patrimônio público, a corrupção, a morosidade judicial, o descrédito na investigação policial, entre outros fatores, representam verdadeiros desafios ao Estado na formulação de políticas públicas.

A participação social na construção da política de segurança pública se faz primordial, uma vez que Estado e sociedade devem agir em conjunto para reforçar a construção de uma nova política, que se afaste dos paradigmas tradicionais. Este pode ser considerado o maior desafio da área de segurança pública para os governos federal, estaduais e municipais e para sociedade.

Nos últimos anos, muitos investimentos foram feitos em Segurança Pública. Por outro lado, é um período marcado por diversas crises, uma vez que o número de rebeliões e de mortes em presídios foi grande, além dos diversos casos de linchamentos, reflexo da sensação de impunidade que leva a sociedade a "fazer justiça com as próprias mãos”. A falta de segurança para exercer suas atividades e o número reduzido de policiais gerou greves por todo o país. A revolta da população contra as ações do governo Dilma Rousseff gerou inúmeras manifestações contra a realização da Copa do Mundo. Hoje, o país ainda enfrenta a crise da rejeição para com o atual governo.

Os dados publicados pelo Fórum Brasileiro de Segurança Pública, de 2014, reforçam que o país convive com taxas absurdas e que o sistema judicial e de segurança são ineficientes. Embora tenha se investido muito na segurança pública, os números aumentaram consideravelmente.

O total de crimes violentos letais intencionais cometidos no Brasil no ano de 2009 foi de 44.518 ocorrências; já em 2013, mesmo com todo esforço para redução da criminalidade, o número subiu para 53.646 ocorrências. Segundo o Fórum Brasileiro de Segurança Pública, de 2014, do total investido em segurança pública na área de Informação e Inteligência em 2012, somente 0,01\% foram para o Estado de Santa Catarina e, em 2013, esse percentual foi de 0,07\%, valor ainda muito baixo. Em 2013, do total investido com Segurança Pública, somente $1,36 \%$ foram em Informação e Inteligência.

Da mesma forma, os números sobre criminalidade no Brasil são assustadores. Dados indicam que nosso país representa $10 \%$ dos casos mundiais de homicídios. Em termos absolutos, é aqui que mais pessoas morrem vítimas de agressão. A marca de um milhão de homicídios foi atingida em 2009, sendo atualmente a principal causa de mortes no país. O apontamento do Mapa da Violência, publicado em 2014, diz que o Brasil, com sua taxa de 27,4 homicídios por 100 mil habitantes, supera largamente os índices dos 12 países mais populosos do mundo. 
Hoje, a estatística de homicídio é o principal indicador de criminalidade utilizado no mundo. Entre os vários fatores que explicam sua utilização, em primeiro lugar, entende-se que o homicídio é um crime que afronta o maior bem jurídico protegido pelo ordenamento pátrio, ou seja, a vida.

Segundo Beato (2012), o Brasil é um dos países mais violentos do mundo, mas sabemos pouco sobre as razões dessa supremacia. Beato afirma ainda que o paradoxo nessa evolução negativa na segurança pública é que ela ocorreu justamente em um período de melhoria generalizada dos indicadores sociais, bem como de fortalecimento das instituições democráticas brasileiras. Sua avaliação é que "todos os esforços de nosso sistema de justiça e de organizações às voltas com segurança pública parecem proteger justamente aqueles que estão menos expostos à violência. A concentração de equipamentos de proteção social, bem como de recursos de segurança pública, se dá de forma desigual" (BEATO, 2012).

Por sua vez, em Santa Catarina, segundo dados da Secretaria de Segurança Pública (SSP), em 2011, o Estado apresentou taxa de 6,34 homicídios para cada 100 mil habitantes no primeiro semestre de 2011, enquanto, no primeiro semestre de 2012, apresentou taxa de 5,78 homicídios. Apesar da redução da taxa de homicídios, na região de Criciúma, onde está localizado o campus Araranguá da Universidade Federal de Santa Catarina (UFSC), houve acréscimo de 11\% no número de ocorrências, que acabou por inclúí-lo no rol das piores taxas do Estado.

O que se pode concluir, e que também já foi apontado pelo Mapa da Violência de anos anteriores, é a interiorização do crime. O aumento antes registrado nas capitais e nos grandes centros urbanos, até 2003, na última década começou a atingir as cidades do interior, as taxas nas capitais ficam estagnadas enquanto no interior continuam crescendo, e isso é agravado pelo fato de essas regiões serem menos protegidas, estarem menos preparadas para a onda de crimes. Esse é o fato que torna essas regiões mais atrativas: a insuficiência da segurança pública em áreas de baixos índices de violência, pois essas regiões não estão preparadas para ações repressivas nem têm efetivos para isso. Isso é agravado pelo fato de que, nas capitais e nos grandes centros, o investimento com segurança é maior, o que proporciona mais eficiência nas ações policiais nessas regiões.

Recentemente, um jovem menor de idade proveniente de Porto Alegre (RS) foi preso em Criciúma, acusado de realizar vários assaltos a prédios comerciais da cidade. Ao ser questionado sobre sua vinda para a região, ele respondeu que "soube" que aqui havia muitos locais de fácil acesso no centro da cidade, com 
pouca ou nenhuma vigilância. ${ }^{1}$ De 2003 a 2011, as taxas das capitais, antes tidas como mais violentas, caíram de 41,6 homicídios por 100 mil para 36,4 em 2011. Em contrapartida, nas cidades do interior, os índices continuam crescendo - houve aumento de 23,6\% no período, segundo dados do Mapa da Violência, de 2014.

Assim como ocorre em nível nacional, também ocorre em Santa Catarina, onde as principais vítimas de homicídio são, de forma exponencial, do sexo masculino, com idades entre 18 e 24 anos e com antecedentes policiais. Perfil idêntico foi identificado no estudo semestral do ano de 2011. Frisa-se também a similaridade de perfis entre o autor e a vítima. Esse perfil da criminalidade aplica-se a quem está mais vulnerável a cometer um crime, tanto a quem está vulnerável a ser vítima dele. Inclui-se ainda a este perfil que estes jovens do sexo masculino são, em sua maioria, moradores de periferia e com baixa escolaridade.

Concordando com Beato (2012), apesar de todas as políticas públicas e investimentos em segurança realizados, existe muito a ser executado em termos de pesquisas, educação e gestão na área de Segurança Pública e Direitos Humanos.

Citando aqui um pouco da história do nosso país, até os anos 1950, o Brasil tinha uma população predominantemente rural; já em 1970, mais da metade da população vivia nas cidades, número que atualmente ultrapassa os $80 \%$. Em pouco tempo, quem trabalhava no campo foi substituído por máquinas e migrou para os grandes centros urbanos, onde a indústria e a construção civil tinham oferta de empregos. Com isso, as cidades cresceram desordenadamente e muito rápido, o que fez crescer a periferia. As cidades não tinham condições de acolher todos, e isso fez surgirem grandes problemas sociais: falta de infraestrutura, saúde, transporte, educação, segurança, ou seja, falta quase tudo. Se o Estado não cria condições de gerar isso tudo, aumenta a criminalidade.

O Mapa da Violência de 2014 aponta Santa Catarina como o estado com os menores índices em relação a outros estados brasileiros, com taxa de 12,6 homicídios por 100 mil habitantes, em 2011. Mas a pesquisa mostra também dois outros índices muito relevantes: que a violência cresceu em relação aos anos anteriores e o crescente aumento da violência dentro do estado, como é o caso da região de Criciúma. Mesmo diante desses dados, não é possível uma acomodação no sentido de se acostumar com o crime, acreditar que a população dessa região está vivendo bem por estar num Estado com um dos menores índices do país, é preciso estar ciente de que a criminalidade cresce a cada dia, e que há um número cada vez maior de presos nos presídios, pois viver na insegurança não pode ser considerado algo comum ou trivial. Pesquisas mostram o aumento das taxas de

1 Notícia veiculada no portal de notícias Engeplus Telecom. Disponível em: <http://www.engeplus. com.br/categoria/seguranca>. Acesso em: 16 maio 2016. 
homicídio em Santa Catarina, cujos registros de homicídios passaram de $653 \mathrm{em}$ 2003 para 816 em 2012.

Ainda com base no Mapa da Violência de 2014, ao se traçar o perfil do crime, aponta-se alguns fatos marcantes que contribuíram para o crescimento da criminalidade na última década em todo o país, como o desarmamento e as estratégias políticas adotadas nos estados mais violentos, no período de 2003 a 2007, gerando assim queda nos índices, seguida de estabilização. Já no período de 2007 a 2012, as taxas voltaram a crescer, com aumento de 15,3\% para o país, passando de 25,2 homicídios em 2007 para 29,0 em 2012. Em Santa Catarina, o aumento foi de mais de 23\%, passando de 10,4 em 2007 para 12,8 em 2012.

Fica claro, pelos dados encontrados durante esta pesquisa, que existem esforços no sentido de reduzir a criminalidade, mas que os dispêndios efetuados são insuficientes e que ainda há muito o que se fazer neste campo. As políticas de segurança pública implantadas no estado são eficazes, mas elas, por si só, não resolverão o problema, uma vez que o estado não está sequer conseguindo estabilizá-los. Os números mostram o aumento exponencial e a sociedade amedrontada clama por ações urgentes.

No que diz respeito ao sistema prisional, também é possível apontar problemas sérios no estado. O governo de Santa Catarina divulgou, em janeiro de 2014, o balanço do sistema prisional, em que aponta que o estado fechou $2013 \mathrm{com}$ 17.200 detentos em suas 48 unidades prisionais, sendo 1.300 mulheres e 15.900 homens, dos quais $57 \%$ com idade entre 18 e 29 anos. No balanço, foi divulgado que, dos 17.200 detentos, 6.600 estão em regime fechado, 3.700 em regime semiaberto, 1.700 em regime aberto e 5.200 são presos que aguardam julgamento (SANTA CATARINA, 2015).

O Tribunal de Contas do Estado de Santa Catarina realizou em 2014, entre os dias 24 de julho e 8 de agosto, uma auditoria operacional com intuito de avaliar a gestão do sistema carcerário do estado. Entre os principais problemas encontrados e citados no relatório técnico da auditoria estão a superlotação, a inexistência de cálculo do custo mensal por preso e de informações sobre reincidência, e a carência de recursos humanos.

Segundo o relatório (SANTA CATARINA, 2013) da Diretoria de Atividades Especiais (DAE), em 2012, existiam 49 estabelecimentos prisionais, sendo 44 deles administrados exclusivamente pela Secretaria de Justiça e Cidadania (SJC), autogestão ${ }^{2}$ e cinco operados por cogestão ${ }^{3}$. A auditoria indicou população car-

2 Autogestão: forma de gestão do estabelecimento prisional em que a SJC é integralmente responsável pela administração da unidade.

3 Cogestão: a SJC contrata empresa para realizar a execução de serviços técnicos e materiais para a operacionalização das unidades, mas a Secretaria permanece com a direção do estabelecimento penal. 
cerária de 14.905 presos naquele período, sendo que 44 dos estabelecimentos apresentaram superlotação, gerando déficit de 4.474 vagas, além de apontamentos quanto à carência de 931 agentes prisionais e de 131 profissionais da área da saúde e assistência social para que fossem cumpridos os padrões definidos pelo Conselho Nacional de Política Criminal e Penitenciária.

Os dados apontam ainda que há uma série de inversões de valores no país, daí os desafios em erradicar os fatores que originam a violência. Esses atos intimidam a sociedade, que vive em situação de risco, em um Estado Democrático de Direito. O que assusta não é somente a falta de identificação do autor de um crime, mas também a ausência de uma punição coerente com o crime cometido. $\mathrm{O}$ fato de criminosos rapidamente estarem livres para repetirem atos criminosos faz com que a população se sinta encarcerada: é a sociedade quem está ficando reclusa, sem poder exercer seu direito de ir e vir.

\section{CONSIDERAC̣ÕES FINAIS}

São muitas as consequências que este aumento da violência urbana tem causado. É fato que a solução para esses problemas não envolve apenas a segurança pública; é preciso melhorias no sistema público como um todo. Em uma sociedade em que não se recebe boa educação, não tem moradia, oportunidades de emprego, acesso ao sistema de saúde, entre outros fatores, certamente haverá aumento no índice criminal. A solução envolve, portanto, mudanças nas políticas públicas e na sociedade.

As cidades são locais de convivência humana, de troca de experiências, de contato direto com outras pessoas, enfim, são espaços que promovem o acesso à informação, e para que isso aconteça, é preciso criar condições e fornecer a segurança necessária. Porém, a realidade dos últimos anos é bem diferente disso: a divulgação intensiva de crimes e da violência urbana promove a insegurança, gera o medo e a sensação de desamparo, que comumente são vinculados ao estado, tido como ausente no provimento de segurança pública.

Esse sentimento da população reflete também no governo, que acaba criando leis na base do imediatismo, tomado pela emergência da situação. São ações que não são de prevenção, aspecto que é fundamental para a redução da violência.

Conclui-se, com este estudo, que as políticas de segurança pública precisam mais do que investimentos no setor. Não basta construir novos presídios, tem que haver uma reforma penal, a legislação precisa caminhar junto com a segurança, é preciso criar meios para que as forças policiais possam combater e prevenir ações criminosas. Vale destacar que não há investimentos com planejamento estratégico em gestão da tecnologia, informação e conhecimento direcionados à segurança pública. 
A ausência ou omissão do Estado é uma das principais causas da criminalidade, por deixar faltar os direitos básicos do cidadão. A desigualdade social também é uma causa importante, assim como a má distribuição de renda do país só vem agravar a situação. Os jovens da periferia também querem ter roupas de marca, acesso as tecnologias da "moda" e, como não conseguem por meio do trabalho, acabam partindo para o lado do crime, no qual esses itens podem ser adquiridos.

Outra causa importante do aumento da violência é a ação dos traficantes de drogas. A relação do tráfico com o crime é extensa, não somente pela ação do traficante, mas também pelo fato de esses traficantes estarem cientes das leis do país, que acabam por colocar os jovens menores de idade na mira dos traficantes. Eles são, de certa forma, obrigados a cometer o crime. Não há como restabelecer a ordem pública se os autores de graves delitos não forem punidos.

É preciso urgentemente uma reforma no Código Penal, pois os criminosos estão se valendo das leis atuais, nas quais predomina a impunidade. Medidas preventivas devem ser tomadas para combater a criminalidade. E para que possam existir tais medidas, a lei precisa ser atualizada, pois hoje não se cometem somente os crimes que existiam em 1988. Se o crime é culpa das desigualdades sociais, é preciso lutar para acabar com elas e não colocar jovens que cometem crimes de volta às ruas só porque eles são vítimas da sociedade.

Os poucos investimentos na segurança pública geraram impactos para o Estado de Santa Catarina. O aumento da criminalidade reflete-se não apenas nas ocorrências registradas pela polícia, mas também no número de efetivos na rua em determinados horários e localidades, programas em locais de maior incidência de crimes e voltados para as pessoas mais vulneráveis a ele. Porém, o mais importante é que a garantia dos direitos previstos na Constituição Federal para os detentos não pode, em nenhum momento ou situação, prevalecer sobre a garantia dos direitos dos cidadãos e dos profissionais de segurança pública.

Sapori (2012) reitera com a seguinte afirmação:

A reversão desse triste quadro exige que a sociedade brasileira transforme a segurança pública em verdadeira prioridade política. Não se trata apenas de alocação de mais recursos públicos para o setor. A tarefa que se apresenta é a reforma do arranjo institucional da segurança pública previsto na Constituição Federal, que se mostra anacrônico diante da realidade atual. Necessitamos de um esforço coletivo similar àquele empreendido para o controle da inflação em meados da década de 1990 (SAPORI, 2012, p 157).

Reconhecer que o Estado deve investir ainda mais em segurança é um fato, porém, espera-se que os direitos dos cidadãos, previstos na Constituição Federal, sejam resguardados e que os direitos daqueles que cometem crimes não se sobreponham em qualquer situação aos direitos dos profissionais da segurança pública e dos cidadãos. 


\section{REFERÊNCIAS}

ADORNO, S. Insegurança versus direitos humanos: entre a lei e a ordem. Tempo Social Rev. Sociol. USP, São Paulo, v.11, n.2, p.129-153, out. 1999 (edit. fev. 2000). . Exclusão sócio-econômica e violência urbana. In: TAVARES DOS SANTOS, J. V.; BAUMGARTEN, M. (ed.). Sociologias - Violências, América Latina. Revista Semestral do Programa de Pós-Graduação em Sociologia da UFRGS, Porto Alegre, n.8. jul./dez. 2002, p. 84-135. Disponível em: <http://www.nevusp.org/portugues/index. php? option=com_content\&task=view\&id=1060\&Itemid=96>Acesso em: 7 jun. 2015. BEATO, C. Crime e Cidades. Belo Horizonte: UFMG, 2012.

BRAGA JÚNIOR, M. O conceito de polícia e a noção de segurança no contexto atual dos direitos Humanos. In: BITTAR, E. C. B. (Org.) Direitos Humanos no século XXI: Cenários de Tensão. Rio de Janeiro: Forense Universitária, 2009.

BRASIL. Ministério da Justiça Secretaria Nacional de Segurança Pública/SENASP. Matriz Curricular Nacional: Para Ações Formativas dos Profissionais da Área de Segurança Pública. 2009. Disponível em: <http://posticsenasp.ufsc.br/files/2014/02/2009 MatrizCurricular.pdf> Acesso em: 7 jun. 2015.

Ministério da Justiça. Secretaria Nacional de Segurança Pública. Programa de Ciência e Tecnologia aplicada na Área de Segurança Pública. Brasília: 2007.

. Presidência da República. Secretaria de Direitos Humanos. Plano Nacional de Educação em Direitos Humanos. 2015. Disponível em: <http://www.sdh.gov.br/sobre/ participacao-social/cnedh>. Acesso em: 7 jun. 2015.

Presidência da República. Secretaria de Direitos Humanos. Programa Nacional de Direitos Humanos 3. 2010. Disponível em <http://www.sdh.gov.br/assuntos/direitopara-todos/programas/pdfs/programa-nacional-de-direitos-humanos-pndh-3>. Acesso em: 7 jun. 2015.

- Secretaria Geral da Presidência da República. Mapa da Violência 2012: os novos padrões da violência homicida no Brasil. 1.ed. São Paulo: Instituto Sangari, 2011. Disponível em: <http://www.mapadaviolencia.org.br/>. Acesso em: 20 jun. 2015.

. Secretaria-Geral da Presidência da República. Mapa da Violência 2014. 2014. Brasília: 2014. Disponível em: <http://www.mapadaviolencia.org.br/>. Acesso em: 20 jun. 2015. FELTRAN, G. S. Fronteiras de Tensão: Política e Violência nas Periferias de São Paulo. São Paulo: Unesp, 2012.

LOPES, E. Política e segurança pública: uma vontade de sujeição. Rio de Janeiro: Contraponto, 2009. Disponível em: <http://www.sapientia.pucsp.br/tde_arquivos/3/TDE2007-06-13T09:38:59Z-3474/Publico/Edson\%20Lopes.pdf>. Acesso em: 7 jun. 2015.

LUNARDI, G. M. O direito à segurança enquanto direito humano: liberdade versus segurança pública. $8^{\circ}$ Encontro da ANDHEP - Políticas Públicas para a Segurança Pública e Direitos Humanos, São Paulo, 28-30 abr. 2014. Faculdade de Direito USP, 2014.

PEREIRA, P. A. P. Discussões conceituais sobre política social como política pública e de direito de cidadania. In: BOSCHETTI, I. (Org.). Política social no capitalismo: tendências contemporâneas. São Paulo: Cortez, 2009. 
SALLA, F. Os impasses da democracia brasileira: o balanço de uma década de políticas para as prisões no Brasil. Revista Lusotopie, Paris, v.10, p. 419-435, 2003.

SANTA CATARINA. Secretaria de Estado de Comunicação. Balanço do Sistema Prisional 2013. Disponível em: <http://www.sc.gov.br/mais-sobre-seguranca-publica/scdivulga-balanco-do-sistema-prisional>. Acesso em: 20 jun. 2015.

. Secretária de Estado e do Planejamento. Pacto por SC. Disponível em: <http:// www.pactoporsc.sc.gov.br/>. Acesso em: 7 jun. 2015.

. Tribunal de Contas do Estado. Auditoria no Sistema Prisional Catarinense. Florianopólis. 10 dez. 2014. Disponível em: <http://www.tce.sc.gov.br/acom-intranet/ noticia/23413/tcesc-faz-radiografia-do-sistema-prisional-catarinense>. Acesso em: 20 jun. 2015.

SAPORI, L. F. Segurança pública no Brasil: desafios e perspectivas. Rio de Janeiro: Editora FGV, 2007. . Avanço no socioeconômico, retrocesso na segurança pública: paradoxo brasileiro? Revista de Ciências Sociais da PUC-Rio, n.11, ago./dez. 2012, p. 133-158. SOARES, L. E. A Política Nacional de Segurança Pública: histórico, dilemas e perspectivas. Estudos Avançados, São Paulo, v.21, n.61, 2007, p. 91-92. SOUZA, C. Políticas Públicas: uma revisão da literatura. Sociologias, Porto Alegre, ano 8, n.16, jul./dez. 2006, p. 20-45. 
